International Journal of Engineering \& Technology, $7(4.1)(2018) 86-89$
International Journal of Engineering \& Technology
SPC
Website: ww. sciencepubco.com/index.php/IJET
Research paperer

\title{
Different Structural Modification Methods of the Patch for Reducing the Size of An Microstrip Patch Antenna
}

\author{
Nayla Ferdous*, Goh Chin Hock, Saidatul Hamidah A. Hamid, Mohamad Nazri Abdul Raman, Tiong Sieh \\ Kiong, Mahamod Ismail \\ College of Engineering, Universiti Tenaga Nasional, Kajang , Malaysia \\ *Corresponding author E-mail: Nayla.Ferdous@uniten.edu.my
}

\begin{abstract}
The aim of this paper is to present a simulation and analysis of a rectangular microstrip patch antenna with three different structural modifications to reduce the size of the antenna. We have tried to decrease the size of the antenna by inducing three different shaped slits inside the patch of the antenna. All these models have been designed and analyzed using CST Microwave Studio software. For designing the antennas, Flame Retardant 4 (FR-4 lossy) has been used as the substrate material with a dielectric constant of $\mathrm{Er}=4.3$. The antenna works at the frequency of $2.4 \mathrm{GHz}$. Performance characteristics such as return loss S11 parameter<-10 dB, directivity, side lobe level, gain and bandwidth of each of the modified designs are obtained and compared with the original design. We were able to reduce the size by maximum $18 \%$ and minimum $7 \%$ by only inducing the slits, while maintain the performance.
\end{abstract}

Keywords: $2.4 \mathrm{GHz}$ band; Antenna patches; Microstrip patch antenna; Miniaturization; Structural modification.

\section{Introduction}

Recent advancement in wireless communication technology demands more and more compact devices. So, it has become very crucial to miniaturize the individual building block of the wireless communication system. Antenna is a key component of the wireless communication systems. It is believed that antenna is an individual block which takes most of the real estate in a modern wireless communication system [1]. So, miniaturization of the antenna can really help to reduce the size of the wireless communication device. But it is a very challenging task to reduce the size of the antenna as doing so can also affect the performance of the antenna. This is very important to focus on the parameters of the antenna like return loss, radiation pattern, gain and efficiency while reducing the size of the antenna because that also hampers these parameters.

Microstrip patch antennas are currently receiving considerable amount of attention for using in wireless communication devices. These antennas are highly flexible in design, shape and conformability thus allowing for relatively easy miniaturization and integration inside the compact wireless communication devices [2]

But a major limitation of microstrip patch antenna is low efficiency and narrow impedance bandwidth, which makes the miniaturization more challenging without compromising the basic parameters.

At lower frequencies the size of the microstrip antennas becomes large. In modern communication systems the compact microstrip patch antennas are desirable. There are various techniques to reduce the size of the microstrip antennas. One of which is to structurally modify the antenna to decrease the size of the antenna by increasing the electrical length of the antenna.

\section{Basic structure of microstrip patch antenna}

A simple microstrip patch antenna has a radiating patch on one side of the substrate material and ground plane on the other side. Microstrip antennas has the basic structures as below [3]:

Patch: This is the radiating conductive element of the antenna and it can be of different shapes and sizes.

Substrate: This isolates the radiating patch from the ground plane \& characterized by its permittivity.

Ground plane: This is a conductor which works as ground for the circuit.

Feedline: This is used to excite the circuit by guiding the current to it by direct or indirect contact.

The basic structure of a microstrip patch antenna is shown in Figure 1 .

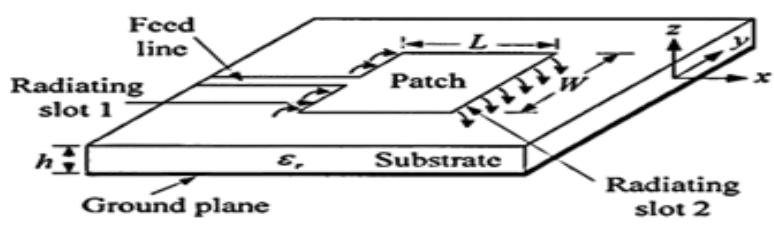

Fig. 1: Basic structure of microstrip patch antenna

\section{Miniaturization techniques}

The use of patch designs for wireless communication antennas allows for several additional miniaturization techniques. The main focus of miniaturization is to decrease the size of the antenna at a 
certain frequency, but to conserve the sufficient electromagnetic performance. Miniaturization techniques for patch antennas include:

1. Using high-permittivity dielectric (substrate/ superstrate) materials [4]: high-permittivity dielectrics can be used as substrate material to reduce the size of the antenna because they shorten the effective wavelength and result in lower resonance frequencies, thus assisting in antenna miniaturization.

2. Insertion of shorting pins [5]: Adding a shorting pin between the ground and conducting plane increases the electrical length of the antenna, and, in turn, decreases the required visible dimensions for a specific operating-frequency scenario.

3. Patch-stacking [6]: Piling two or more radiating patches vertically reduces antenna size by increasing (nearly doubling) the length of the current-flow path.

4. Structural modification [1]: Another way to reduce the size of microstrip antenna is by modifying its shape, by inserting slot to meander currents.

In our case we have chosen to reduce the size of the antenna by three different structural modifications.

\section{Antenna design and simulation:}

We have intended to design an antenna which works at $2.4 \mathrm{GHz}$ resonant frequency. We have used copper as the radiating material and FR-4 $(\varepsilon r=4.3, \tan \delta=0.015)$. At first we have designed an elementary edge fed rectangular patch antenna and observed its performance. Then we have tried to reduce the size of the antenna by inducing different slits inside the patch while maintaining the performance. CST microwave studio has been used to design and simulate the antenna. The performance of the antenna has been observed accurately and then they have been compared.

\subsection{Fundamental design}

Firstly, the antenna has been designed theoretically for the allocated frequency band. For designing the antenna equation has been used. In (1) is for calculating the Length of the patch of the antenna for a selected frequency.

$$
\mathrm{L}_{\mathrm{T}}=\frac{c}{4 f_{r} \sqrt{\xi}}
$$

Where, $\mathrm{c}=$ speed of light $\mathrm{fr}=$ resonance frequency of the antenna $\xi=$ dielectric constant of the substrate material The parameters used to design the antenna is given in Table 1 . The design of the antenna is shown in Figure 2. The simulation results of the designed antenna are as shown in Figure 3. \& Figure 4.

Table 1: Design Parameters

\begin{tabular}{cc}
\hline Parameter & Measurements (mm) \\
\hline Patch Length & 28.4 \\
Patch Width & 45 \\
Substrate Length & 58.4 \\
Substrate Width & 50 \\
Heigth of Substrate & 1.6 \\
Matching line Length & 10 \\
Matching line Width & 0.8 \\
Feeding line Length & 15 \\
Feeding line Width & 2.9 \\
\hline
\end{tabular}

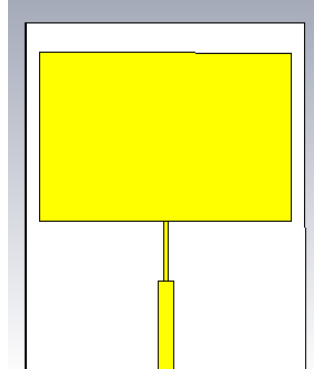

Fig.2: Basic design of the patch antenna

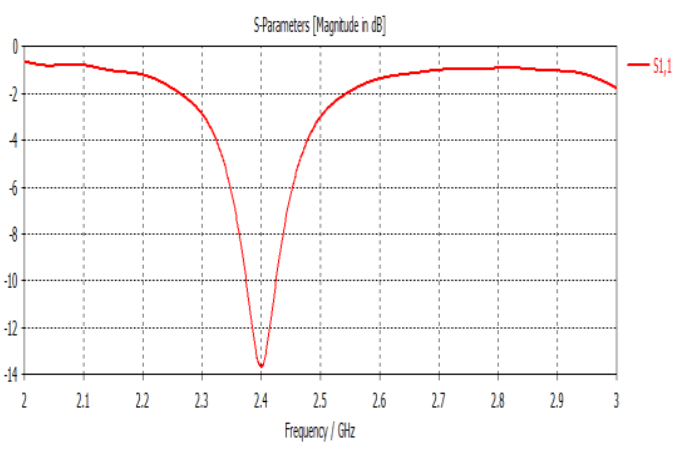

Fig. 3: Return loss or $\mathrm{S} 11$ parameter of the basic antenna
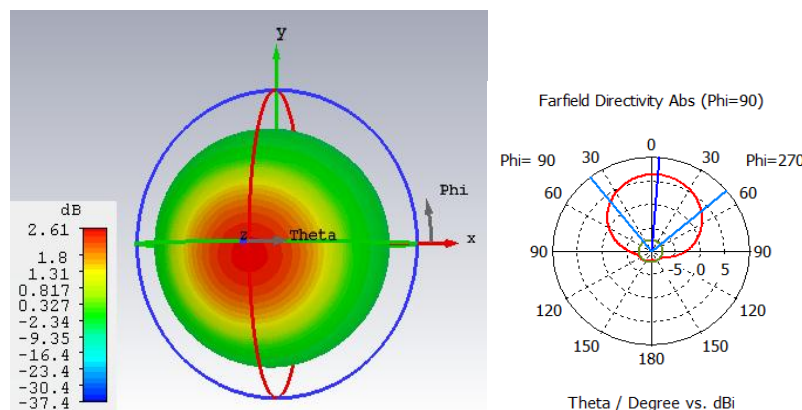

Theta / Degree vs. dB

Fig. 4: (a)Farfield radiation pattern in 3D form (b) Farfield directiviy in polar form

\subsection{Antenna design with structural modifications}

This section discusses the simulation design and results of different structurally modified models to increase the electrical length of the antenna hence decrease the physical size of the antenna

\subsubsection{Antenna with cross slit}

The parameters used to design the antenna is given in Table 2. The design of the antenna is shown in Figure 5. The simulation results of the designed antenna are as shown in Figure 6 \& Figure 7.

Table 2: Design Parameter of first modification

\begin{tabular}{cc}
\hline \multicolumn{2}{c}{ Table 2: Design Parameter of first modification } \\
\hline Parameter & Measurements $(\mathbf{m m})$ \\
\hline Patch Length & 26.35 \\
Patch Width & 45 \\
Substrate Length & 56.35 \\
Substrate Width & 50 \\
Heigth of Substrate & 1.6 \\
Matching line Length & 10 \\
Matching line Width & 0.8 \\
Feeding line Length & 15 \\
Feeding line Width & 2.9 \\
\hline
\end{tabular}




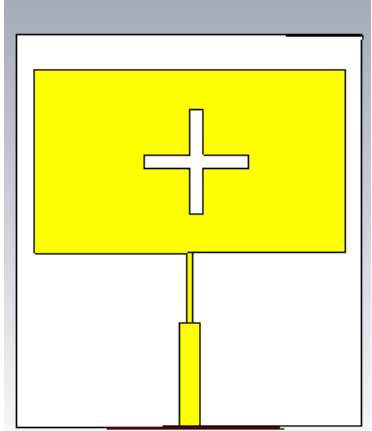

Fig. 5: Structural modification of the patch with cross slit

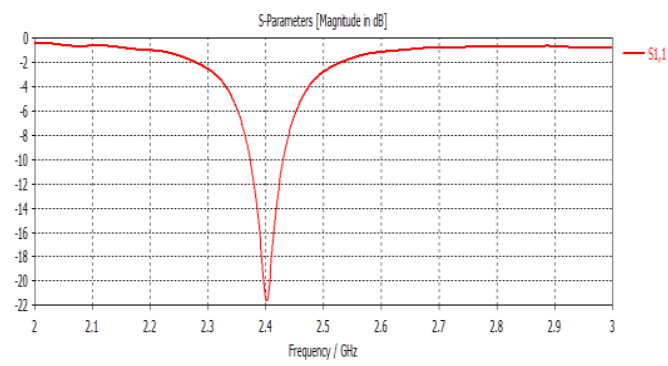

Fig. 6: Return loss or S11 parameter

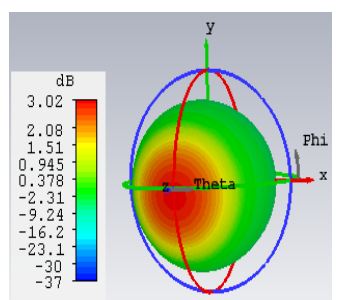

Farfield Directivity Abs (Phi=90)

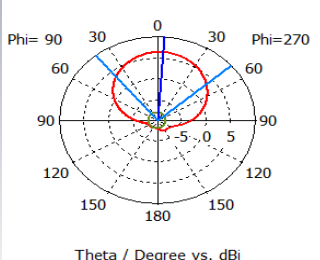

Theta / Dearee vs. dBi

Fig. 7: (a) Farfield radiation pattern in 3D (b) Farfield directivty in polar form

\subsubsection{Antenna with rectangular slit}

The parameters used to design the antenna is given in Table 3 . The design of the antenna is shown in Figure 8. The simulation results of the designed antenna are as shown in Figure $9 \&$ Figure 10.

Table 3: Design parameter of second modification Parameter Measurements (mm)

Patch Length Patch Width

Substrate Length

Substrate Width

Heigth of Substrate

Matching line Length

Matching line Width

Feeding line Length

Feeding line Width

\begin{tabular}{l}
26 \\
45 \\
56 \\
50 \\
1.6 \\
10 \\
0.8 \\
15 \\
2.9 \\
\hline
\end{tabular}

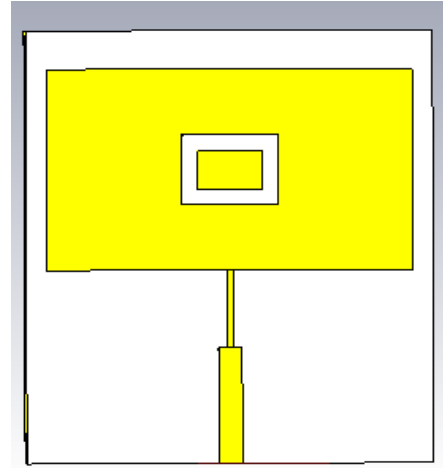

Fig. 8: Structural modification of the patch with rectangular slit

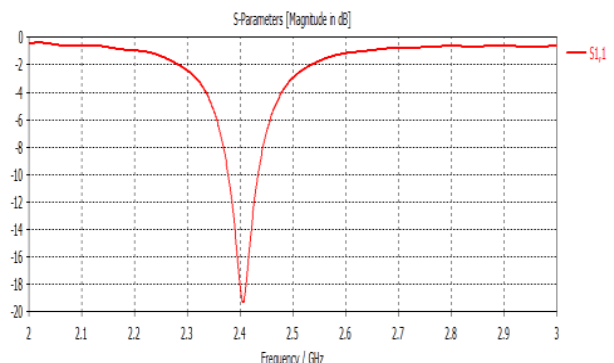

Fig. 9: Return Loss or S11 parameter
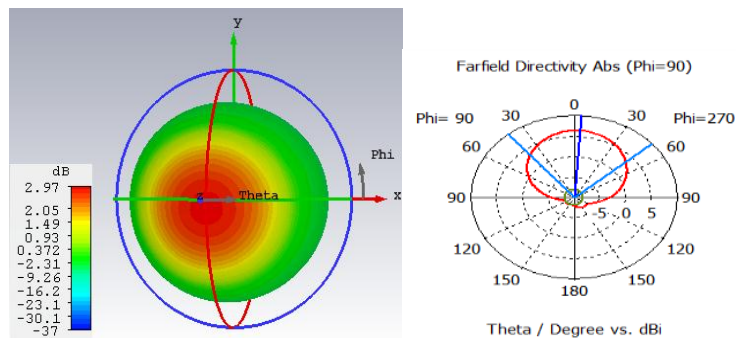

Fig 10: (a)Farfield radiation pattern in 3D (b) Farfield directivty in polar form

\subsubsection{Antenna with $S$ shaped slit}

The parameters used to design the antenna is given in Table 4 . The design of the antenna is shown in Figure 11. The simulation results of the designed antenna are as shown in Figure $12 \&$ Figure 13.

\begin{tabular}{|c|c|}
\hline Parameter & Measurements (mm) \\
\hline Patch Length & 23.25 \\
\hline Patch Width & 45 \\
\hline Substrate Length & 53.25 \\
\hline Substrate Width & 50 \\
\hline Heigth of Substrate & 1.6 \\
\hline Matching line Length & 10 \\
\hline Matching line Width & 0.8 \\
\hline Feeding line Length & 15 \\
\hline Feeding line Width & 2.9 \\
\hline
\end{tabular}

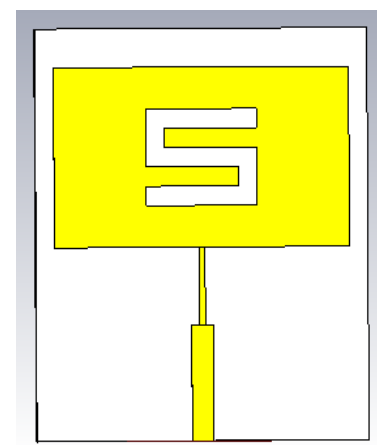

Fig 11: Structural modification with s shaped slit

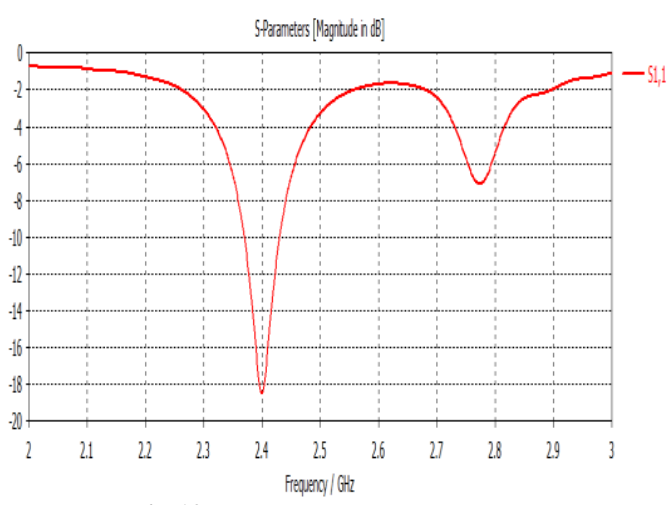

Fig 12: Return Loss or S11 parameter 

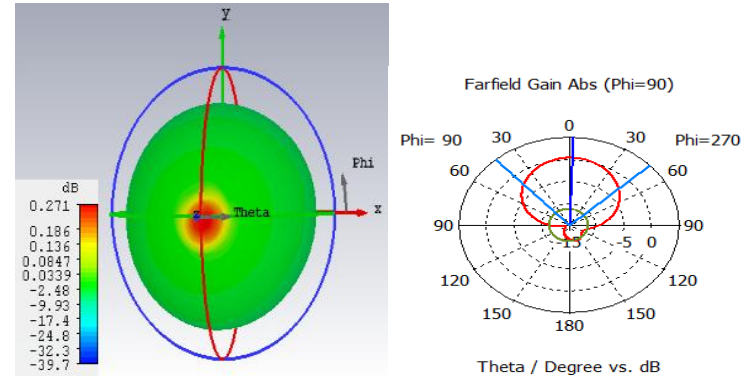

Fig 13: (a) Farfield radiation pattern in 3D (b) Farfield directivty in polar form

\section{Results and analysis}

The results from all the designed antenna has been discussed in this section. The comparison of the result has been presented in Table 5 .

Table 5: Comparison of all performance of the antennas

\begin{tabular}{|l|l|l|l|l|}
\hline \multirow{2}{*}{ Parameter } & \multicolumn{4}{|c|}{ Rectangular Antenna Patch Type } \\
\cline { 2 - 5 } & Basic & $\begin{array}{l}\text { With } \\
\text { cross slit }\end{array}$ & $\begin{array}{l}\text { With rec- } \\
\text { tangular } \\
\text { slit }\end{array}$ & $\begin{array}{l}\text { with s } \\
\text { shaped } \\
\text { slit }\end{array}$ \\
\hline $\begin{array}{l}\text { Return Loss } \mathrm{S}_{11} \\
\text { (dB) }\end{array}$ & -13.65 & -21.63 & -19.34 & -21.36 \\
$\begin{array}{l}\text { Directivity (dBi) } \\
\text { Gain (dB) }\end{array}$ & 6.3 & 6.3 & 6.3 & 6.13 \\
$\begin{array}{l}\text { Band Width } \\
\text { (MHz) }\end{array}$ & 2.615 & 3.03 & 2.98 & 0.5 \\
$\begin{array}{l}\text { Side Lobe Level } \\
\text { (dB) }\end{array}$ & -13.8 & -14.3 & -14.4 & 60.7 \\
$\begin{array}{l}\text { Patch Size } \\
\text { (LengthXWidth) } \\
\text { (mmXmm) }\end{array}$ & $28.4 X 45$ & $26.35 X 45$ & $26 X 45$ & $23.25 \mathrm{X} 42$ \\
$\begin{array}{l}\text { Size Reduced } \\
\text { (\%) }\end{array}$ & ------ & 7.21 & 8.5 & 18.12 \\
\hline
\end{tabular}

The basic antenna has a return loss of $-13.65 \mathrm{~dB}$, the antenna gain is $2.615 \mathrm{~dB}$ and the the main lobe magnitude of the directivity of the antenna is $6.3 \mathrm{dBi}$, the side lobe level is $-13.8 \mathrm{~dB}$ and bandwidth is $50.8 \mathrm{MHz}$

Then we have induced a cross shaped slit, a rectangular slit and a meandered slit inside the rectangular patch of the antenna.

The dimension of the antenna with cross slit is $26.35 \mathrm{mmX} 45 \mathrm{~mm}$. It is $7.21 \%$ less than the actual design. We can see from Table 5, the antenna with cross slit has return loss of $-22.3 \mathrm{~dB}$. The antenna gain is $3.03 \mathrm{~dB}$. and the main lobe magnitude of the directivity of the antenna is $6.3 \mathrm{dBi}$, the side lobe level is $-14.3 \mathrm{~dB}$ and bandwidth is $75.2 \mathrm{MHz}$. This indicates that all the basic parameters are improved by this modification.

The dimension of the antenna with rectangle slit is $26 \mathrm{mmX} 45 \mathrm{~mm}$. It is $8 \%$ less than the actual design. We can see from Table 5 the antenna with cross slit has return loss of $-19.34 \mathrm{~dB}$. The antenna gain is $2.98 \mathrm{~dB}$.and the main lobe magnitude of the directivity of the antenna is $6.3 \mathrm{dBi}$, the side lobe level is $-14.4 \mathrm{~dB}$ and bandwidth is $56.9 \mathrm{MHz}$. This indicates that all the basic parameters are improved by this modification.

The dimension of the antenna with $\mathrm{s}$ shaped slit is $23.25 \mathrm{mmX} 42 \mathrm{~mm}$. It is $18 \%$ less than the actual design. We can see from Table 5, the antenna has a return loss of $-21.36 \mathrm{~dB}$ at $2.4 \mathrm{GHz}$, the antenna gain is $0.5 \mathrm{~dB}$, the main lobe magnitude of the directivity of the antenna is $6.13 \mathrm{dBi}$, side lobe level is $-11.8 \mathrm{~dB}$ and bandwidth is 60.7 . The return loss, the directivity, bandwidth has improved from the original design, but the gain has reduced by this modification the antenna is $2.615 \mathrm{~dB}$ and the main lobe magnitude of the directivity of the antenna is $6.3 \mathrm{dBi}$, the side lobe level is $13.8 \mathrm{~dB}$ and bandwidth is $50.8 \mathrm{MHz}$.

\section{Conclusion}

Here in this paper some structural modifications are presented to reduce size of antenna; each modification has its own merits and demerits. One can use any one or combination of these modifications to reduce size of antenna nearly approximate to requirement. Here structural modified antennas for $2.4 \mathrm{GHz}$ has been designed, without much affecting main parameter for size reduction. The results show a reduction in size as well as return loss.

\section{Acknowledgement}

This research work in Universiti Tenaga Nasional (Uniten) and Institute of Sustainable Energy (ISE) is supported and funded by innovation and Research Management Centre under Smart University Research Grant, grant number: 10289176/SMART/2018/09

\section{References}

[1] Haque SKM \& Parvez KM, "Slot Antenna Miniaturization Using Slit, Strip, and Loop Loading Techniques", IEEE Transactions on Antennas and Propagation, Vol.65, No.5, (2017), pp.2215-2221.

[2] Moghariya D, Kothari T \& Patel MP, "Miniaturisation Method to Reduce the Size of Microstrip Antenna for Lower Frequency", International Journal for Scientific Research \& Development (IJSRD), Vol.1,No.1, (2013), ISSN(online): 2321-0613.

[3] Balanis CA, Modern Antenna Handbook, John Wiley \& Sons, New York, USA, (2008).

[4] Mulla S \& Deshpande SS, "Miniaturization of Micro Strip Antenna: A review", International Conference on Information Processing (ICIP), (2015), pp.372-377.

[5] Chow YL \& Wan KL, "Miniaturizing patch antenna by adding a shorting pin near the feed probe \$a folded monopole equivalent", IEEE Antennas and Propagation Society International Symposium (IEEE Cat. No.02CH37313), (2002), pp.6-9.

[6] Kumar S, Gangwar D \& Yadava RL, "Miniaturized inverted multiband stacked triangular fractal patch antenna for wireless communication", 2014 International Conference on Signal Processing and Integrated Networks (SPIN), (2014), pp.267-270. 